\title{
Tuning the Magnetism of Plasma-Synthesized Iron Nitride Nanoparticles: Application in Pervaporative Membranes
}

\author{
Emile Haye, ${ }^{* \dagger}$ ¡ Crosby Soon Chang, ${ }^{\ddagger}$ Gabriela Dudek, ${ }^{\S}$ Thomas Hauet, ${ }^{\ddagger}$ Jaafar Ghanbaja, \\ Yan Busby, ${ }^{\dagger}$ Nathalie Job, ${ }^{\perp}$ Laurent Houssiau, ${ }^{\dagger}$ and Jean-Jacques Pireaux ${ }^{\dagger}$ \\ ${ }^{\dagger}$ Laboratoire Interdisciplinaire de Spectroscopie Electronique, Namur Institute of Structured Matter, University of Namur, 61 rue de \\ Bruxelles, 5000 Namur, Belgium \\ ${ }^{\ddagger}$ Institut Jean Lamour, UMR 7189, Université de Lorraine, 2 Allée André Guinier, 54011 Nancy, France \\ ${ }^{\S}$ Department of Physical Chemistry and Technology of Polymers, Faculty of Chemistry, Silesian University of Technology, 44-100 \\ Gliwice, Poland \\ ${ }^{\perp}$ Department of Chemical Engineering-Nanomaterials, Catalysis, Electrochemistry, University of Liège, Building B6a, 4000 Liège, \\ Belgium
}

\begin{abstract}
The present work reports on the low-pressure, radio-frequency, plasma-driven synthesis of $\varepsilon$ - $\mathrm{Fe}_{3} \mathrm{~N}$-type nanoparticles homogeneously deposited on a high-surface-area porous carbon support, with tunable magnetic properties, directly depending on the plasma treatment conditions. Iron nanoparticles are formed from the degradation of a solid organometallic precursor mixed with a carbon xerogel in a nitrogen-containing (argon/ammonia) plasma discharge. Variation of the working pressure during the plasma treatment directly affects the residence time of the reactive species, which determines the crystalline state of the nanoparticles, from amorphous at low-pressure treatment to well crystallized at high-pressure treatment. This results in a direct influence of the

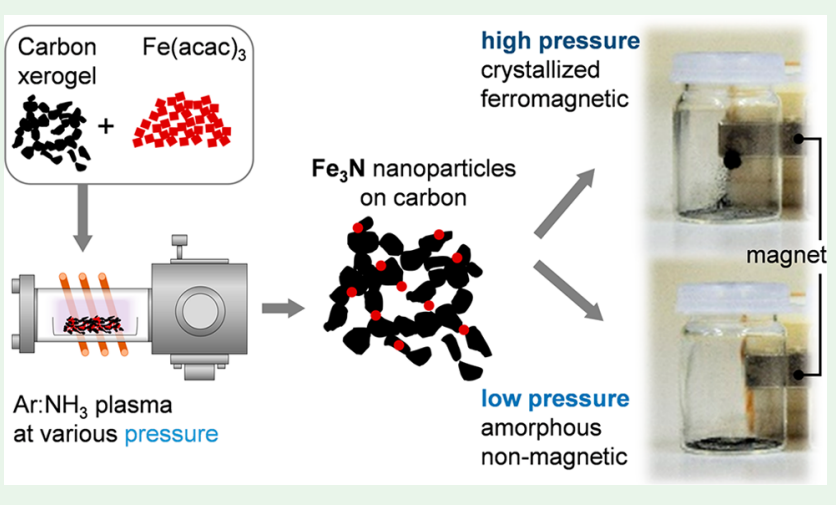
magnetic properties of the iron nitride nanoparticles. The working pressure results in two competing effects because it enhances the crystallinity (at higher pressure) and also slightly affects the surface chemistry of the nanoparticles by increasing the oxygen content, while the last is believed to deteriorate the magnetic properties; however, the crystallinity enhancement dominates. The synthesized $\mathrm{Fe}_{x} \mathrm{~N} / \mathrm{C}_{\mathrm{XG}}$ magnetic composites have been applied as filler materials in alginate membranes for ethanol dehydration in a pervaporation experiment. Results indicate a considerably enhanced performance of the alginate membrane as determined by its selectivity, the separation index, and the flux even when using a small $\mathrm{Fe}_{x} \mathrm{~N} / \mathrm{C}_{\mathrm{XG}}$ loading $(3 \% \mathrm{w} / \mathrm{w})$.
\end{abstract}

KEYWORDS: iron nitride, nanoparticles, radio-frequency plasma, ferromagnetism, pervaporative membrane

\section{INTRODUCTION}

Because of their versatility of chemistry, magnetic properties, and crystallinity, ${ }^{1-3}$ iron nitride nanoparticles are widely used as catalysts $^{4-7}$ and battery materials, ${ }^{8,9}$ and in medical applications. ${ }^{10}$ The low cost and wide physicochemical forms of $\mathrm{Fe}-\mathrm{N}$ compounds bring many advantages compared to noble-metal nanoparticles, such as gold or platinum, for the aforementioned applications. The $\mathrm{Fe}-\mathrm{N}$ system presents numerous different phases, with ferromagnetic compounds such as $\gamma^{\prime}-\mathrm{Fe}_{4} \mathrm{~N}, \alpha^{\prime \prime}$ $\mathrm{Fe}_{16} \mathrm{~N}_{2}$, or $\varepsilon$ - $\mathrm{Fe}_{3} \mathrm{~N}$, while $\mathrm{FeN}$ is paramagnetic.

Most of the conventional synthesis routes of $\mathrm{Fe}_{x} \mathrm{~N}$ nanoparticles are liquid-based processes involving multiple reduction, filtration, and purification steps, as well as the extensive use of solvents, time, and energy. ${ }^{9,11}$ Low-pressure plasma treatments offer a valuable and sustainable alternative processing methodology based on the dry synthesis (solvent-free), allowing for the modification of materials by varying the composition of the plasma atmosphere (i.e., by injecting inert or reactive species) and by using different solid precursors. ${ }^{12,3,13-18}$ Recently, a plasma-based process was developed to synthesize metal nanoparticles on various high-surface-area carbon substrates (graphene, carbon xerogel, and carbon black). The methodology consists of the plasma-induced degradation of a solid organometallic precursor mixed with a carbon substrate, resulting in the formation of metal nanoparticles anchored to the carbon matrix. ${ }^{19-21}$

In this work, we describe the synthesis of magnetic iron nitride nanoparticles $\left(\varepsilon-\mathrm{Fe}_{3} \mathrm{~N}_{x}\right)$ deposited on a carbon xerogel $\left(\mathrm{C}_{\mathrm{XG}}\right)$ 
through the plasma-induced degradation of iron acetylacetonate in a nitrogen-based plasma discharge $\left(\mathrm{Ar} / \mathrm{NH}_{3}\right)$. The plasma environment is a complex medium comprising electrons, reactive ionized species, radicals, and neutral species in nonthermal equilibrium; the working pressure is an easily accessible variable that allows modification of the plasma intensity (electron density and collision rate) and the residence time of the reactive species. The results show that the organometallic precursor is degraded through multiple reactions with the reactive species in the plasma, progressively leading to the growth of $\mathrm{Fe}_{x} \mathrm{~N}$ nanoparticles. Additionally, $\mathrm{Fe}_{x} \mathrm{~N}$ nucleation, growth of the crystalline domains, and, to a lesser extent, their chemistry are found to be directly affected by the total working pressure during the plasma synthesis; this variable is thus chosen to easily control and tune the magnetic properties of the $\mathrm{Fe}_{x} \mathrm{~N}$ nanoparticles.

\section{EXPERIMENTAL SECTION}

Plasma Synthesis of $\mathrm{Fe}_{3} \mathrm{~N} / \mathrm{C}_{\mathrm{XG}}$ Samples. A total mass of $30 \mathrm{mg}$, containing carbon xerogel $\left(\mathrm{C}_{\mathrm{XG}}\right)$ and iron acetylacetonate $\left[\mathrm{Fe}(\mathrm{acac})_{3}\right.$, Acros Organics, $99 \%$ ] to reach a total metal loading of $10 \mathrm{wt} \%$, was introduced in a Petri dish $(\varnothing 30 \mathrm{~mm})$ and treated in a radio-frequency inductively coupled plasma (ICP) reactor working at $13.56 \mathrm{MHz}$ and $200 \mathrm{~W}$ for $1 \mathrm{~h}$. The homogeneous plasma zone is confined in the quartz tube $(\varnothing 150 \mathrm{~mm})$, on a length of $\approx 20-30 \mathrm{~cm}$, sufficiently larger than the sample size. Prior to the treatment, the chamber was pumped down below $5 \times 10^{-5}$ Torr $\left(6.6 \times 10^{-3} \mathrm{~Pa}\right)$ by a turbomolecular pump. Argon and ammonia were flown at 5 and $4 \mathrm{sccm}$, respectively, and the total pressure was adjusted using a throttle valve. The carbon and precursor mixture was treated at four different pressures, namely, 6, 12, 25, and 45 mTorr $(0.8,1.6,3.3$, and $6 \mathrm{~Pa})$. Figure 1 summarizes the plasma synthesis.

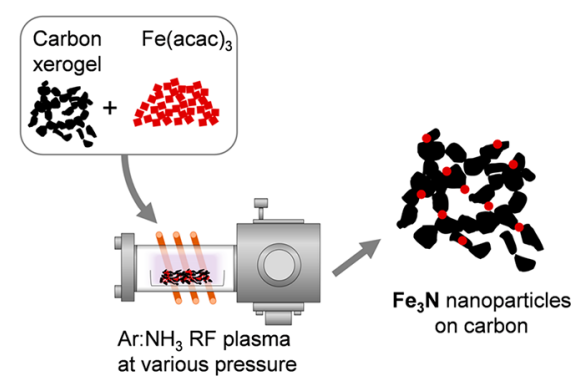

Figure 1. Sketch summarizing the plasma synthesis process of the $\mathrm{Fe}_{3} \mathrm{~N}$ nanoparticles on a xerogel substrate.

Materials Characterization. Powder X-ray diffraction (XRD) measurements were performed in an X'Pert Pro Panalytical diffractometer working with $\mathrm{Cu} \mathrm{K} \alpha$ radiation $(\lambda=1.5406 \AA)$. The surface composition of the sample was investigated by high-resolution $\mathrm{X}$-ray photoelectron spectroscopy (XPS) using a monochromatic $\mathrm{Al} \mathrm{K \alpha}$ source (K-Alpha instrument from Thermo Scientific). High-resolution XPS spectra were acquired at the pass energy of $30 \mathrm{eV}, 0.1 \mathrm{eV}^{\text {step }}{ }^{-1}$, with numbers of scans adjusted from 10 to 40 to get similar signal-tonoise ratios. A flood gun was used for charge compensation, and the spectra were calibrated to the $\mathrm{C} 1 \mathrm{~s}$ peak at $284.8 \mathrm{eV}$ binding energy (BE). The spectra were fitted using Thermo Avantage Software, using a Smart background (Shirley with the additional constraint that the background should not be of a greater intensity than the actual data at any point in the region). Magnetometry measurements were performed on a Quantum Design Physical Property Measurement System equipped with a vibrating sample magnetometer option. The powder samples were placed in gelatin capsules inside plastic-straw sample holders for magnetic characterization. Hysteresis loops were obtained at 5, 10, 20, 50,100, 200, and $300 \mathrm{~K}$, with applied magnetic fields of up to $9 \mathrm{~T}$. Transmission electron microscopy (TEM) investigations were carried out using a JEM-ARM 200F cold field-emission-gun (FEG) TEM/scanning TEM (STEM) operating at $200 \mathrm{kV}$ and equipped with a spherical aberration (Cs) probe and image correctors (point resolution $0.12 \mathrm{~nm}$ in TEM mode and $0.078 \mathrm{~nm}$ in STEM mode). For analysis, samples were sonicated in cyclohexane and a drop was deposited on a copper grid.

Pervaporation Experiment. The pervaporation setup and theoretical background are provided as Supporting Information. The pervaporative experiments were carried out using alginate membranes mixed with the $\mathrm{Fe}_{x} \mathrm{~N} / \mathrm{C}_{\mathrm{XG}}$ nanocomposite synthesized at $45 \mathrm{mTorr}$, i.e., the sample showing the highest magnetism. The membrane, with an effective size of $112 \mathrm{~cm}^{2}$, was synthesized from a $1.5 \mathrm{wt} \%$ sodium alginate solution made by dissolving an appropriate amount of sodium alginate powder in deionized water. The solution was mixed with the $\mathrm{Fe}_{x} \mathrm{~N} / \mathrm{C}_{\mathrm{XG}}$ portion to reach $0,1,3,5$, or $10 \mathrm{wt} \%$. The sodium alginate solution was then cast onto a leveled glass plate and evaporated to dryness at $40{ }^{\circ} \mathrm{C}$. After $24 \mathrm{~h}$, the membrane was cross-linked using calcium chloride. For this, the sodium alginate membrane was immersed in a $2.5 \mathrm{wt} \%$ calcium chloride solution for $120 \mathrm{~min}$ at room temperature. The pristine alginate membrane was prepared following the same methodology except from the addition of $\mathrm{Fe}_{x} \mathrm{~N} /$ $\mathrm{C}_{\mathrm{XG}}$. The casting conditions were optimized to end up with homogeneous membranes with a reproducible thickness, which was measured using an ELMETRON MG-401 waterproof precise coating thickness gauge. The thickness estimated from at least 10 measurements at different locations is $22 \pm 1 \mu \mathrm{m}$. The membrane was placed on a finely porous stainless steel plate support. After ethanol/water separation within the membrane module, the retentate was recirculated to the feed tank and the permeate was received and frozen in the cold trap. The compositions of the feed, permeate, and retentate were analyzed by gas chromatography on a PerkinElmer Clarus 500 gas chromatograph equipped with a $30 \mathrm{~m}$ Elite-WAX ETR column and a flame ionization detector.

\section{RESULTS AND DISCUSSION}

Structural Property Analysis. Degradation of the organometallic precursor and subsequent crystallization of $\mathrm{Fe}_{x} \mathrm{~N}$ domains by the plasma treatment at various total working pressures between 6 and 45 mTorr were investigated by XRD measurements (Figure 2a). The working pressure was simply
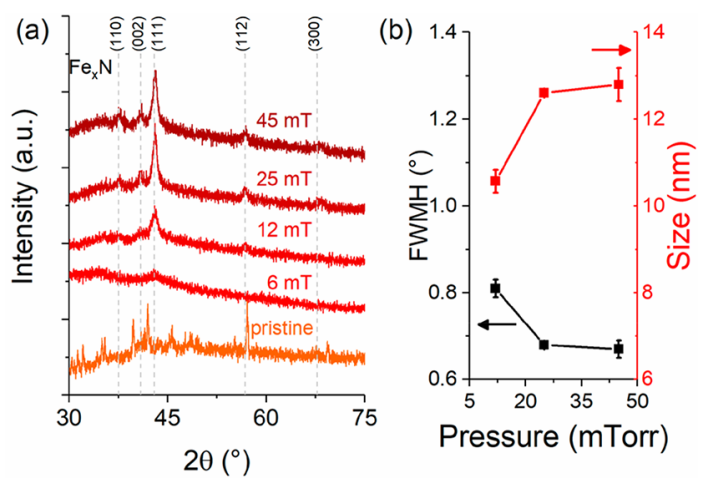

Figure 2. (a) XRD measurements of the untreated powder mixture of the precursors (pristine) and the $\mathrm{Fe}_{x} \mathrm{~N} / \mathrm{C}_{\mathrm{XG}}$ composites obtained by $\mathrm{Ar} / \mathrm{NH}_{3}$ plasma treatments at various total working pressures. (b) Variation of the FWHM of the most intense reflection (111) and the derived domain size using the Scherrer formula.

increased by reducing the pumping speed thanks to an intermediate throttle valve. The obtained diffraction peak positions possibly indicate the formation of $\mathrm{Fe}_{2} \mathrm{~N}$ or $\mathrm{Fe}_{3} \mathrm{~N}$ trigonal structures [space group P312 (No. 149)] or $\varepsilon-\mathrm{Fe}_{3} \mathrm{~N}$ hexagonal iron nitride structures [space group $\mathrm{PG}_{3} 22$ (No. $182)]$. Because of the very similar XRD patterns, it is difficult to 
discriminate between $\mathrm{Fe}_{2} \mathrm{~N}, \mathrm{Fe}_{3} \mathrm{~N}, \varepsilon-\mathrm{Fe}_{3} \mathrm{~N}$, or other intermediate structures $\left(\mathrm{Fe}_{3} \mathrm{~N}_{1.1}, \mathrm{Fe}_{3} \mathrm{~N}_{1.33}, \ldots, \mathrm{Fe}_{3} \mathrm{~N}_{1.5}\right){ }^{22,23}$ Despite this complication, based on the relative peak intensities and positions, the experimental XRD patterns obtained at various pressure values result in the best agreement with the $\varepsilon-\mathrm{Fe}_{3} \mathrm{~N}_{1.33}$ (hexagonal) structure, ${ }^{23}$ but a mixture of $\mathrm{Fe}_{2} \mathrm{~N}$ and $\mathrm{Fe}_{3} \mathrm{~N}$ is not excluded. A deeper investigation of the structure is presented later, based on TEM measurement. The XRD patterns indicate that nanoparticles synthesized at $6 \mathrm{mT}$ orr are almost amorphous because the diffraction peaks are not clearly defined. With an increase of the treatment pressure, the main features of the XRD pattern do not change; however, one clearly observes a reduction of the full width at half-maximum (FWHM) of the (111) diffraction peak (Figure 2b). On the basis of the DebyeScherrer formula, a decrease of the FWHM can be correlated with an increase of the average crystal domain size from $\sim 10.5$ $\mathrm{nm}$ (at 12 mTorr) to $\sim 13 \mathrm{~nm}$ (at $45 \mathrm{mTorr}$ ).

The size distributions of $\mathrm{Fe}_{x} \mathrm{~N}$ nanoparticles on the carbon xerogel were further investigated by STEM (Figure 3). Overall, the micrographs confirm that homogeneously dispersed nanoparticles decorate uniformly the porous carbon surface. In agreement with the $\mathrm{XRD}$ analysis, an increase of the total working pressure results in an increase in the average particle size; however, as was frequently reported, the XRD analysis tends to overestimate the domain size because of the highly weighted particle aggregates. The selected-area electron diffraction (SAED) patterns present very diffuse and unclear rings for nanoparticles at $6 \mathrm{mTorr}$ (Figure 3c), suggesting amorphous or poorly crystallized nanoparticles. In contrast, at 45 mTorr, the reflection is more intense and more defined (Figure 3d), in accordance with crystallized nanoparticles, with the possibility of indexing several planes at $d=0.163,0.210$, 0.221 , and $0.239 \mathrm{~nm}$.

The experimental values $d_{\exp }$ determined on Figure $2 \mathrm{~d}$ have been compared with the reported values $d_{\text {theo }}$ for several iron nitride structures. We compared our $d_{\exp }$ values with the $\mathrm{Fe}_{2} \mathrm{~N}$ trigonal structure (SG 149, work from Hendricks and Kosting ${ }^{24}$ ), $\mathrm{Fe}_{3} \mathrm{~N}$ trigonal structure ( $\mathrm{SG}$ 149, work from Hendricks and $\mathrm{Kosting}^{24}$ and $\mathrm{Jack}^{22}$ ), $\varepsilon-\mathrm{Fe}_{3} \mathrm{~N}$ hexagonal structure ( $\mathrm{SG}$ 182, work from Jacobs et al. ${ }^{25}$ ), and $\varepsilon$ - $\mathrm{Fe}_{3} \mathrm{~N}_{1+x}$ hexagonal structure (SG 182), with $x$ ranging from 0.1 to 0.39 (work from Leineweber et al. ${ }^{23}$ ). Table 1 presents a comparison with the relative error $\delta$ given in percent.

Considering the uncertainty in the determination of $d_{\text {exp }}$, the lowest differences are obtained with the $\mathrm{Fe}_{2} \mathrm{~N}$ trigonal structure ${ }^{24}$ and $\mathrm{Fe}_{3} \mathrm{~N}_{1.33}$ hexagonal structure, ${ }^{23}$ with similar $\delta$ of $0.2-0.3 \%$, while the difference reaches several percent for other structures. However, $\mathrm{Fe}_{2} \mathrm{~N}$ does not present ferromagnetic behavior, ${ }^{26,27}$ suggesting an indexation in agreement with the $\mathrm{Fe}_{3} \mathrm{~N}_{1.33}$ structure.

Chemical Property Analysis. The evolution of the sample chemistry as a function of the plasma synthesis pressure was investigated by energy-dispersive spectroscopy (EDS) measurement (Table 2) and XPS chemical analysis of the Fe 2p, O 1s, and $\mathrm{N} 1$ s core levels (Figure 4). The quantification from XPS analysis is not reliable because it is a surface composition that can be influenced by the morphology of the sample (nanoparticle size). Even if EDS is generally not recommended for the quantification of light elements, a recent work from Woodward et al. suggests that it is can be used to investigate the chemical composition of nanoparticles. ${ }^{16}$ In the present work, EDS analysis has only been used for a qualitative comparison of the concentrations of iron, oxygen, and carbon. Nitrogen was not

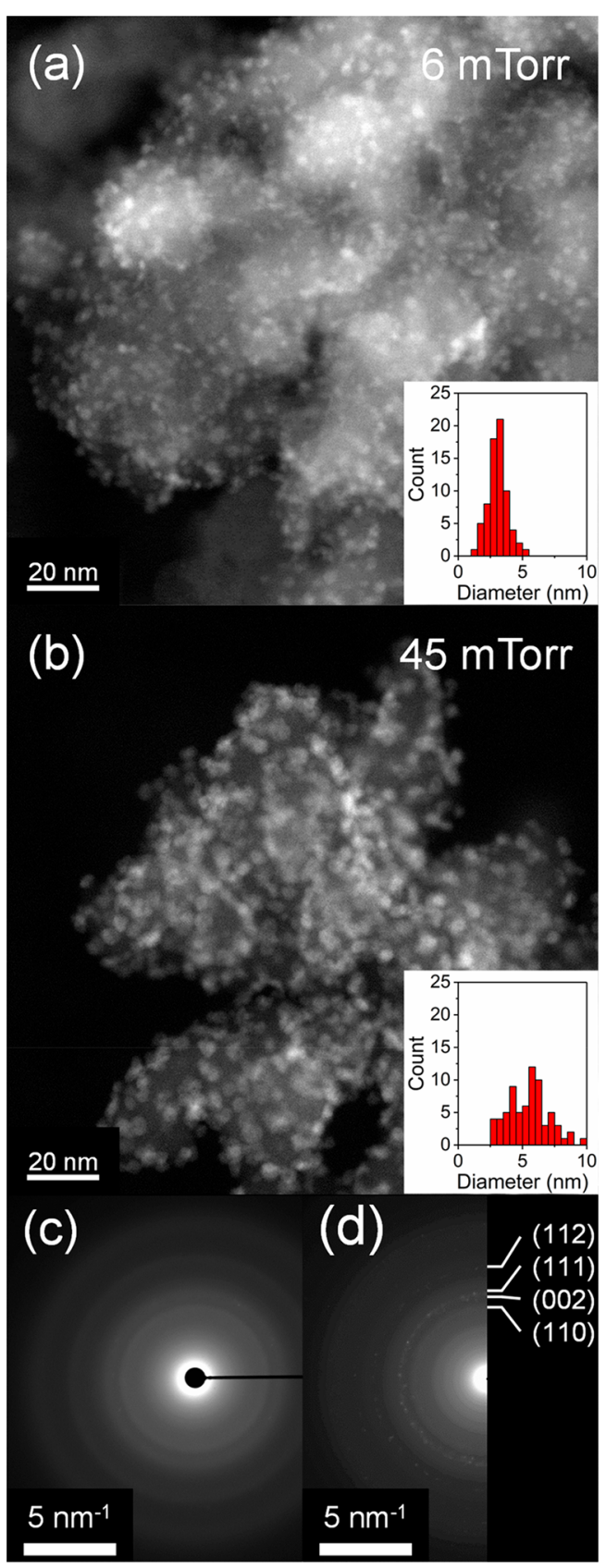

Figure 3. High-angle annular dark-field STEM micrographs of samples treated under (a) 6 mTorr and (b) $45 \mathrm{mTorr}$, with the nanoparticle size distributions in the insets. SAED patterns of samples treated under (c) 6 mTorr and (d) 45 mTorr.

quantified because its discrimination with oxygen on EDS spectra is challenging in the case of low nitrogen content. The quantification (Table 2) exhibits a similar concentration for samples synthesized at 12,25 , and 45 mTorr. The sample synthesized at $6 \mathrm{mT}$ Torr contains a higher oxygen content.

In addition to EDS measurements, which give a rough estimation of the global composition of the sample, the highresolution XPS spectra of $\mathrm{O} 1 \mathrm{~s}, \mathrm{~N} 1 \mathrm{~s}$, and Fe 2p have been fitted, giving information on the nanoparticle chemistry. We only present the fits for the $6 \mathrm{~m}$ Torr sample and the relative variation of each contribution as a function of the pressure, but all of the fits are given in Figure S-1. 
Table 1. Comparison of Experimental $d$ Values for (112), (111), (002), and (110) Planes with Several Iron Nitride Structures

\begin{tabular}{|c|c|c|c|c|c|}
\hline & & \multicolumn{4}{|c|}{ plane } \\
\hline & & (112) & (111) & $(002)$ & $(110)$ \\
\hline this work & $d_{\exp }(\mathrm{nm})$ & $0.162(9)$ & $0.210(1)$ & $0.221(3)$ & $0.239(1)$ \\
\hline ref 24 & $d_{\text {theo }}(\mathrm{nm})$ & 0.1624 & 0.2106 & 0.2209 & 0.2397 \\
\hline $\mathrm{Fe}_{2} \mathrm{~N}$ trigonal (SG 149) & $\delta_{\text {theo/exp }}(\%)$ & 0.30 & 0.26 & 0.20 & 0.23 \\
\hline ref 24 & $d_{\text {theo }}(\mathrm{nm})$ & 0.1593 & 0.2058 & 0.2181 & 0.2334 \\
\hline $\mathrm{Fe}_{3} \mathrm{~N}$ trigonal (SG 149) & $\delta_{\text {theo/exp }}(\%)$ & 2.26 & 2.09 & 1.47 & 2.44 \\
\hline ref 22 & $d_{\text {theo }}(\mathrm{nm})$ & 0.1607 & 0.2078 & 0.2197 & 0.2358 \\
\hline $\mathrm{Fe}_{3} \mathrm{~N}$ trigonal (SG 149) & $\delta_{\text {theo/exp }}(\%)$ & 1.34 & 1.12 & 0.73 & 1.40 \\
\hline ref 25 & $d_{\text {theo }}(\mathrm{nm})$ & 0.1584 & 0.2081 & 0.2161 & 0.2329 \\
\hline $\mathrm{Fe}_{3} \mathrm{~N}$ hexagonal (SG 182) & $\delta_{\text {theo/exp }}(\%)$ & 2.82 & 0.98 & 2.40 & 2.65 \\
\hline $\operatorname{ref} 23$ & $d_{\text {theo }}(\mathrm{nm})$ & 0.1608 & 0.2079 & 0.2197 & 0.2360 \\
\hline $\mathrm{Fe}_{3} \mathrm{~N}_{1.1}$ hexagonal (SG 182) & $\delta_{\text {theo/exp }}(\%)$ & 1.30 & 1.06 & 0.71 & 1.32 \\
\hline ref 23 & $d_{\text {theo }}(\mathrm{nm})$ & 0.1620 & 0.2099 & 0.2208 & 0.2386 \\
\hline $\mathrm{Fe}_{3} \mathrm{~N}_{1.33}$ hexagonal (SG 182) & $\delta_{\text {theo/exp }}(\%)$ & 0.56 & 0.10 & 0.23 & 0.21 \\
\hline
\end{tabular}

Table 2. Estimated Mass Concentrations of Samples from EDS Measurements

\begin{tabular}{cccc} 
& \multicolumn{3}{c}{ mass concentration (wt \%) } \\
\cline { 2 - 4 } pressure (mTorr) & Fe & O & C \\
6 & $6 \pm 1$ & $22 \pm 1$ & $72 \pm 1$ \\
12 & $11 \pm 1$ & $16 \pm 1$ & $73 \pm 2$ \\
25 & $12 \pm 2$ & $17 \pm 2$ & $71 \pm 3$ \\
45 & $14 \pm 2$ & $18 \pm 1$ & $68 \pm 1$ \\
\hline
\end{tabular}

The $\mathrm{O}$ 1s spectra (Figure 4a) feature three chemical components, attributed to $\mathrm{O}-$ metal (at $529.8 \mathrm{eV}$ ), $\mathrm{O}-\mathrm{C}$ or
$\mathrm{O}-\mathrm{H}($ at $531.6 \mathrm{eV})$, and $\mathrm{O}$ in water (at $533.6 \mathrm{eV}) .^{28,29}$ The Fe $2 \mathrm{p}$ doublet spectra (Figure $4 \mathrm{~b}$ ) indicate the presence of $\mathrm{Fe}^{0}$ $\left(2 \mathrm{p}_{3 / 2}\right.$ at $\left.707.6 \mathrm{eV}\right), \mathrm{Fe}^{2+}(711.0 \mathrm{eV})$, and $\mathrm{Fe}^{3+}(713.7 \mathrm{eV})$ chemical states. ${ }^{28,30}$ For simplicity, satellite peaks in the $\mathrm{BE}$ range of 717-721 eV have been fitted with a single component, with the corresponding doublet at $\approx 732 \mathrm{eV}$. The $\mathrm{N} 1$ s spectra (Figure 4c) feature three chemical components corresponding to pyridinic nitrogen (at $399.4 \mathrm{eV}$ ), pyrrolic nitrogen (at 403.3 $\mathrm{eV}),{ }^{19,28}$ and iron nitride/oxynitride (at $\left.396.7 \mathrm{eV}\right) .^{29,31}$ Many XPS studies have been previously devoted to fitting the $\mathrm{N} 1 \mathrm{~s}$ spectrum in iron nitride/oxynitrides and other transition-metal nitrides to evidence the evolution of the spectrum with the
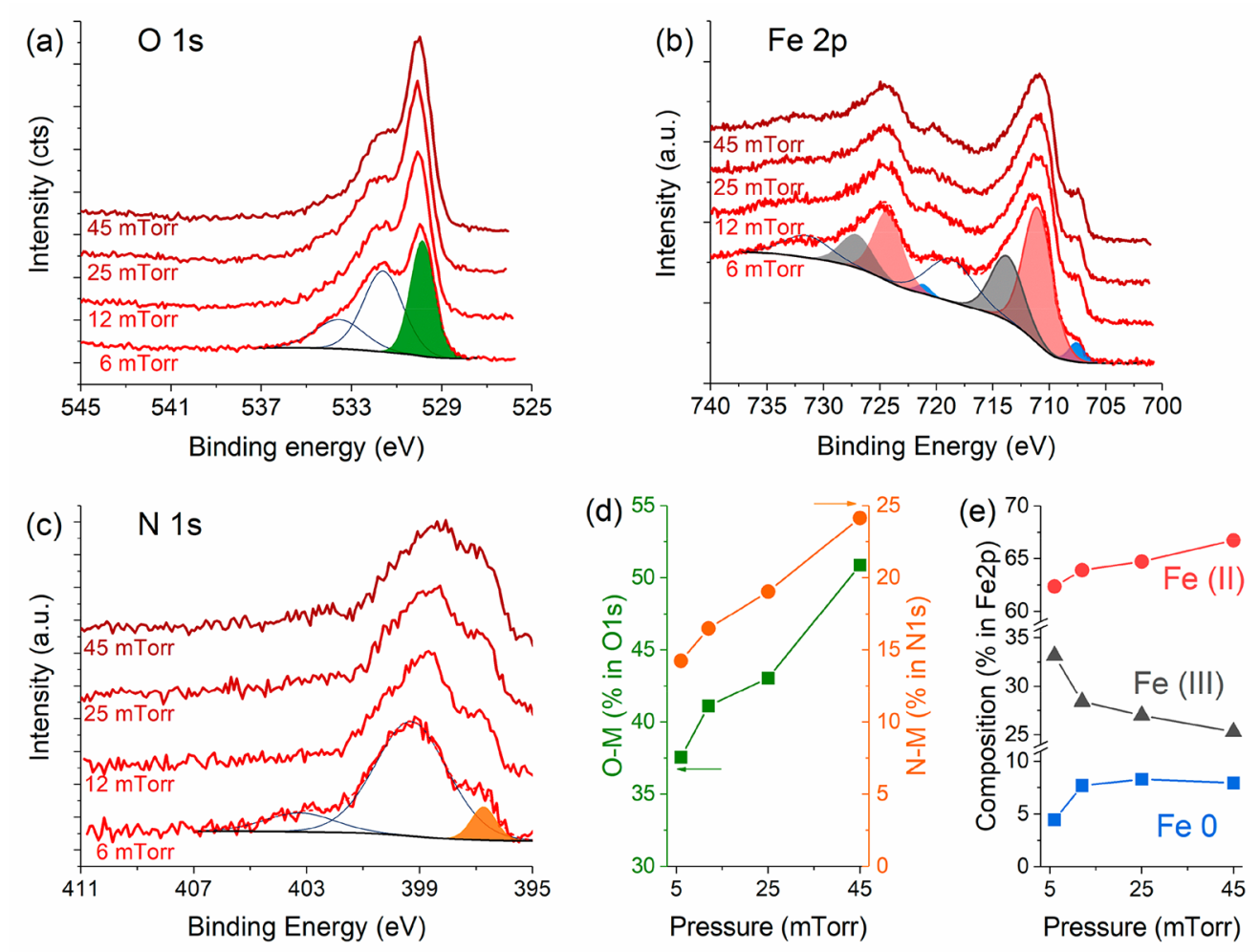

Figure 4. Evolution of the (a) O 1s, (b) Fe 2p, and (c) N 1s core-level XPS spectra as a function of the total working pressure during the plasma synthesis. (d) Evolution of the $\mathrm{O}-$ metal and $\mathrm{N}$-metal percentages within the respective $\mathrm{O}$ 1s and $\mathrm{N}$ 1s core-level spectra. (e) Evolution of the percentage of the three components within the Fe $2 \mathrm{p}$ peak as a function of the plasma pressure. 

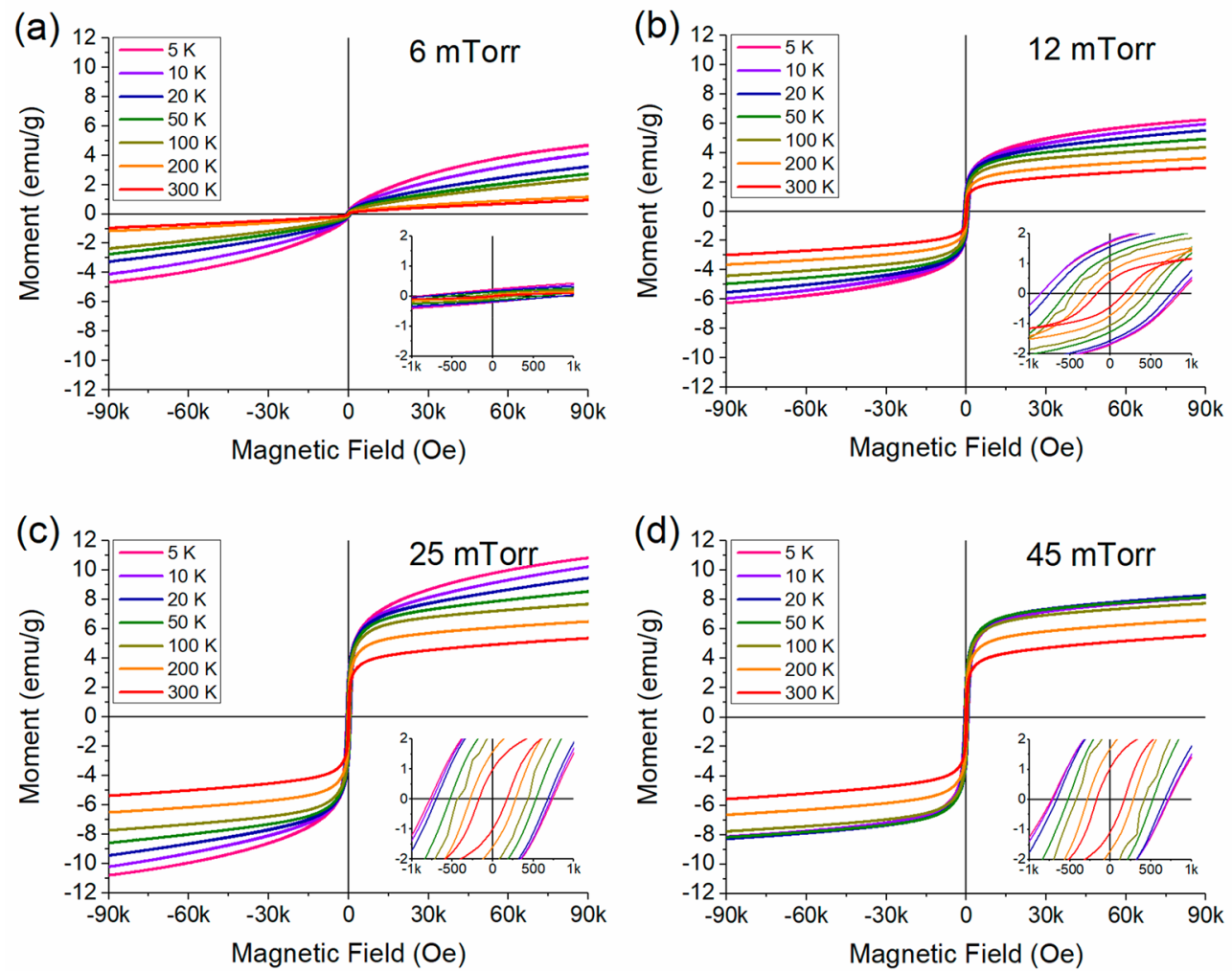

Figure 5. $M(H)$ loop curves of $\mathrm{Fe}_{3} \mathrm{~N} / \mathrm{C}_{\mathrm{XG}}$ treated at (a) 6, (b) 12, (c) 25, and (d) $45 \mathrm{mTorr}$.

oxygen content: the oxynitride peak (at $396.1 \mathrm{eV}$ ) was generally found to shift about $1 \mathrm{eV}$ toward low BEs with respect to the nitride peak $(397.4 \mathrm{eV}) .^{29,32-35}$ The reason for this shift was ascribed to the increase of charge transfer from the metal to the nitrogen atom when the oxynitride is formed. ${ }^{34}$ Here, with the calibration of $\mathrm{C} 1 \mathrm{~s}$ at $284.8 \mathrm{eV}$, the nitride/oxynitride $\mathrm{N} 1 \mathrm{~s}$ component is centered at $396.7 \mathrm{eV}$ (with a FWHM value of 1.4 $\mathrm{eV}$ ), suggesting a balanced mixture between the two chemical states (nitride and oxynitride). Looking at samples synthesized at various pressures, this nitride/oxynitride contribution, together with the $\mathrm{O}-$ metal contribution in the $\mathrm{O} 1 \mathrm{~s}$ spectrum, increases with increasing plasma synthesis pressure (Figure $4 d$ ), indicating a potential oxynitridation of the nanoparticles at higher pressure. This trend is associated with an overall reduction of iron (Figure 4e), confirming the higher incorporation of nitrogen $\left(\mathrm{N}^{3-}\right.$ instead of $\left.\mathrm{O}^{2-}\right)$. The large presence of the $\mathrm{O}$-metal contribution is due to the oxidation of iron nitride nanoparticles, as frequently reported. ${ }^{36-38}$

Some conclusions based on the chemical analysis can be derived about the precursor degradation mechanism, as well as the nanoparticle nucleation and growth. Indeed, an increase of the total working pressure, within the studied range, increases the reactivity of the plasma because of a higher electron density, ${ }^{39}$ a higher number of collisions, and a higher radiation intensity (attested by more intense light emission). These three phenomena boost the degradation rate of the organometallic precursor and the subsequent nanoparticle germination (nucleation of iron clusters); they also enhance the probability of nitrogen species to react with seed particles. Once the seed particles are formed, they are exposed to the reactive plasma environment where several physical, chemical, and thermal mechanisms may occur, including ion etching, oxidation, nitridation, and heating. ${ }^{19,40,41}$ The global composition indicates a high oxygen content $(\approx 20 \mathrm{wt} \%)$, which is attributed to the release of oxygen from the reactor walls and/or from the carbon xerogel. ${ }^{19,42-44}$ The composition is not significantly affected by the pressure except at $6 \mathrm{mTorr}$, where higher oxygen content is observed, which may be attributed to some remains of the precursor. However, the XPS analysis revealed modification of the oxygen localization, which is more bound to iron at higher pressure. This indicates that the higher reactivity of the plasma at high pressure promotes the incorporation of oxygen into the $\mathrm{Fe}_{x} \mathrm{~N}$ nanoparticles to form oxynitrides. ${ }^{45-47}$ XRD and electron diffraction patterns does not indicate the presence of iron oxide phases; this suggests that oxygen is incorporated into a thin amorphous oxide layer or, more probably, in the nitride structure. Moreover, the increase of the working pressure induces a higher heat exchange (by collisions), which results in the rise of the sample surface temperature and, consequently, allows for a higher mobility for iron species to diffuse and form larger and more crystallized nanoparticles. ${ }^{41,48}$ The increase of the crystallization at higher working pressure is in agreement with a recent work from Kramer et al., ${ }^{48}$ which suggested that the crystallization of nanoparticles directly depends on the plasma reactivity.

Magnetic Property Analysis. The magnetic properties of all synthesized samples were characterized by vibrating sample magnetometry at temperatures from 5 to $300 \mathrm{~K}$, with the applied magnetic field $(H)$ intensity up to $\pm 9 \mathrm{~T}$ (Figure 5). The magnetic moment values are reported in electromagnetic units (emu) per mass unit of the sample (which contains about $10 \mathrm{wt}$ $\%$ iron). Within the four samples synthesized at different working pressures, we observe the following trends: (i) the total magnetic moment $(M)$ looks like a mixture of ferromagnetic signals, as is evident from the hysteretic behavior at low field (as shown in the insets), and paramagnetic and/or super- 
paramagnetic signals, as is evident from the overall Langevin-like shape of the magnetization curves at high field. For the samples synthesized at low pressure, the paramagnetic/superparamagnetic signal dominates, while a stronger ferromagnetic behavior dominates in the samples synthesized at higher working pressure.

Among the multiple stable $\mathrm{Fe}-\mathrm{N}$ nitride phases, $\alpha^{\prime \prime}-\mathrm{Fe}_{16} \mathrm{~N}_{2}$, $\gamma^{\prime}-\mathrm{Fe}_{4} \mathrm{~N}$, and $\varepsilon-\mathrm{Fe}_{3} \mathrm{~N}$ exhibit ferromagnetism properties, ${ }^{49}$ while $\mathrm{Fe}_{2} \mathrm{~N}$ does not present ferromagnetic behavior. ${ }^{26,27}$ The presence of a ferromagnetic phase, as indicated by magnetometry analysis, is consistent with the XRD and TEM results, pointing out formation of the $\varepsilon-\mathrm{Fe}_{3} \mathrm{~N}$ phase, which is known to be ferromagnetic.

From analysis of the $M$ versus $H$ curves, we can extract some useful quantitative parameters to quantitatively compare of the ferromagnetic properties of each sample. The coercivity $H_{c}$ (the applied field required to reach the zero net moment) and the remanence $M_{\mathrm{r}}$ (the magnetic moment at zero applied field) can both be trivially extracted from the hysteresis loops (as shown in the insets of Figure 5).

The derivation of the saturation magnetization $\left(M_{\mathrm{s}}\right)$ from the experimental curves is indirect because the saturation regime is not achieved as a result of the persisting paramagnetic signal, which is superposed over the ferromagnetic signal. One way to extract $M_{\mathrm{s}}$ is to fit the curve with the so-called "Law of Approach to Saturation" ${ }^{\text {50,51 }}$ based on the following equation:

$$
M=M_{S}\left[1-\frac{a}{H}-\frac{b}{H^{2}}\right]+\chi H
$$

This equation is valid for a pure ferromagnet, where $M_{s}$ is the saturation magnetization, $a$ is a parameter related to magnetic hardness, $b$ is a parameter related to anisotropy, $\chi$ is the total diamagnetic and paramagnetic susceptibility, and $H$ is the magnetic field. Here we will only focus on comparing the obtained $M_{\mathrm{s}}$ values.

Because eq 1 assumes a linear $\chi H$ term, the relationship is only valid for curves where $M(H)$ is linear, i.e., at sufficiently large magnetic field and temperature (here above $50 \mathrm{~K}$ ). The values of $H_{\mathcal{c}}, M_{\mathrm{s}}$, and $M_{\mathrm{r}}$ extracted from the $M(H)$ loop curves are plotted in Figure 6 as a function of the plasma synthesis pressure and for various measurement temperatures. The fitting parameters are given in the Supporting Information.

Overall, the plasma pressure strongly influences the magnetic properties. At $45 \mathrm{mT}$ orr, the nanocomposite exhibits the highest $M_{\mathrm{s}}$ values of $7.4 \mathrm{emu} \mathrm{g}^{-1}$ at $50 \mathrm{~K}$ and above $4.5 \mathrm{emu} \mathrm{g}^{-1}$ at room temperature (Figure $6 \mathrm{~b}$ ). At the lowest working pressure (6 mTorr), the $M_{\mathrm{s}}$ value drops to below $1 \mathrm{emu} \mathrm{g}^{-1}$ with almost no temperature dependence. The sample synthesized at $45 \mathrm{mTorr}$ also shows a remanent magnetization at $5 \mathrm{~K}$ of $M_{\mathrm{r}}=3 \mathrm{emu} \mathrm{g}^{-1}$ (Figure 6c). The latter disappears in the samples synthesized at lower working pressure.

The previous work reported saturation magnetization values ranging from 15.2 to $130 \mathrm{emu} \mathrm{g}^{-1}$ at $5 \mathrm{~K},{ }^{11,49,52,53}$ with bulk $\varepsilon$ $\mathrm{Fe}_{3} \mathrm{~N}$ having a saturation magnetization of $133 \mathrm{emu} \mathrm{g}^{-1} \cdot 37,54$ Taking into account that our samples contained about $10 \%$ $\mathrm{FeN}_{x}$ by mass, our measured saturation magnetization values are consistent with the values from the literature.

The magnetic properties of $\varepsilon-\mathrm{Fe}_{3} \mathrm{~N}$ have been investigated in several previous works. ${ }^{26,36,37,49}$ The magnetic moment arises from the unbalanced distribution between spin-up and spindown states, mostly coming from $\mathrm{Fe} 3 \mathrm{~d}$ and $\mathrm{N} 2 \mathrm{p}$ in $\varepsilon-\mathrm{Fe}_{3} \mathrm{~N}$. ${ }^{36,55}$ Panda and Gajbhiye and Rohith Vinod et al. ${ }^{36,55}$ describe electron exchange, giving the $\mathrm{Fe}-\mathrm{N}$ bond a covalent behavior

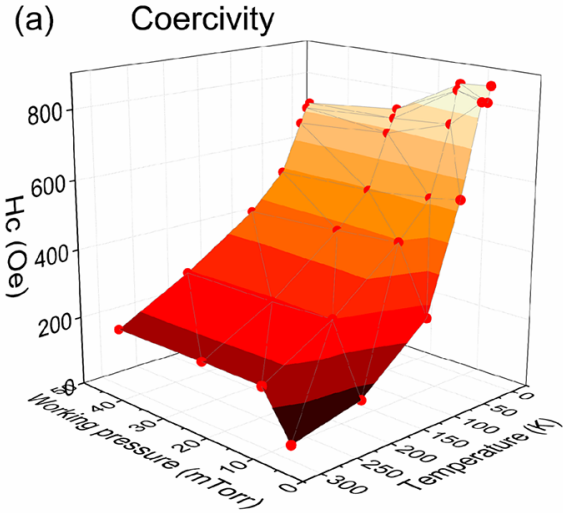

(b) Saturation magnetization

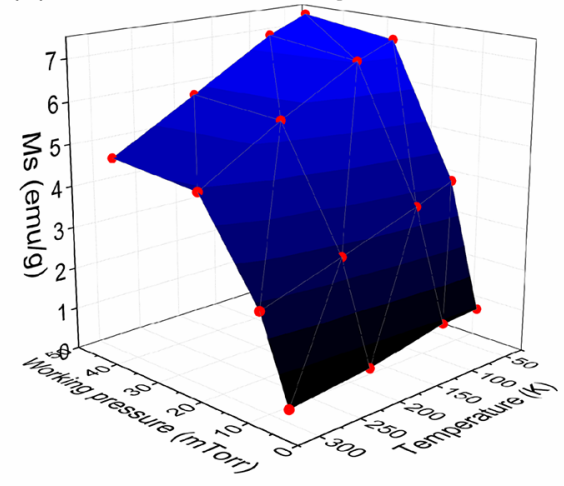

(c) Remanent magnetization

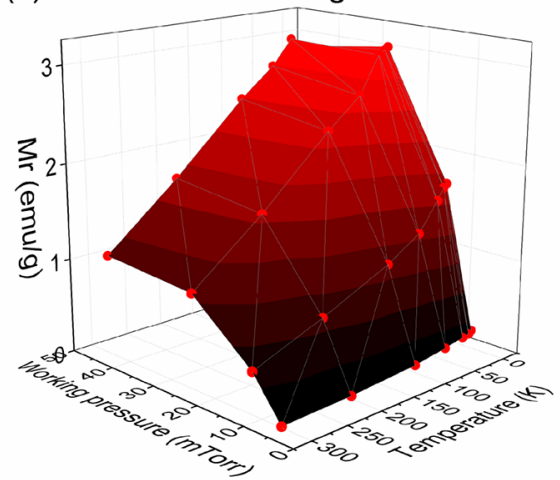

Figure 6. Evolution of the (a) coercivity $H_{c}$, (b) saturation magnetization $M_{\mathrm{s}}$ and (c) remanent magnetization $M_{\mathrm{r}}$ as a function of the plasma treatment pressure (6-45 mTorr) and measurement temperature $(5-300 \mathrm{~K})$.

but, at the same time, nitrogen acts as an electron donor, enhancing an ionic-type bonding. As a consequence, the number of unpaired $\mathrm{d}$ electrons diminishes, lowering the magnetization of $\varepsilon$ - $\mathrm{Fe}_{3} \mathrm{~N}$ compared to $\alpha$-Fe. It is known that the magnetization strongly evolves with the nitrogen content, lattice expansion, particle size, and crystalline structure. ${ }^{22,27,36,49,53}$ Reducing the pressure in the plasma synthesis leads to a reduction of both the crystalline state, from well crystallized to amorphous nanoparticles, and particle size. These, in turn, affect the unbalanced charge distribution between spin-up and spin-down states, responsible for the net magnetic moment, and ultimately for a decrease of the saturation magnetization.

Finally, the larger crystallite size at high pressure would favor ferromagnetism because of the lower alteration of the unbalanced charge distribution between the N 2p and Fe $3 d$ 
states; one would thus expect that the increase of the oxygen content in the nanoparticles synthesized at high pressure (see Figure 4) should result in a reduction of $M_{s}{ }^{56,57}$ Surprisingly, this effect is not observed, meaning that the higher crystallinity dominates over oxidation. This might be due to the fact that oxidation affects the nanoparticle surface, which does not sensibly contribute to the magnetic properties.

Application to Pervaporative Dehydration of an Ethanol/Water Mixture. Pervaporative dehydration is an effective and energy-efficient method in which a membrane is used to separate the constituents of an azeotropic composition (e.g., solvent and water). This method is frequently used for ethanol dehydration because this separation is difficult to achieve by conventional separation processes. The membrane is generally composed of a permselective polymer (alginate and chitosan), which improves the performance of the membrane. Recent works have focused on membrane loading with the addition of magnetic nanoparticles in order to increase the water diffusivity within the membrane, while keeping a constant (or even decreasing) ethanol diffusivity. ${ }^{58,59}$

The pervaporative membrane performance depends on (i) the transport properties and (ii) the separation effectiveness. The transport properties are measured with regard to the flux $\left(J_{\mathrm{N}}\right.$, in $\mathrm{kg}$ $\mathrm{m}^{-2} \mathrm{~h}^{-1}$ ), the permeation coefficient of each species (ethanol and water here, $P_{\text {water }}$ and $P_{\mathrm{EtOH}}$ measured in barrer), the diffusion coefficients $\left(D_{\text {water }}\right.$ and $D_{\mathrm{EtOH}}$ in $\mathrm{cm}^{2} \mathrm{~s}^{-1}$ ), the solubilities $\left(S_{\text {water }}\right.$ and $S_{\mathrm{EtOH}}$ in $\left.\mathrm{cm}_{\mathrm{sccm}}{ }^{3} \mathrm{~cm}^{-3} \mathrm{cmHg}^{-1}\right)$, and the selectivity coefficient $\left(S_{c}\right)$. The separation effectiveness is measured through the separation factor $\alpha_{\mathrm{H}_{2} \mathrm{O} / \mathrm{EtOH}}$ and the pervaporation separation index (PSI in $\mathrm{kg} \mathrm{m}^{-2} \mathrm{~h}^{-1}$ ). The methodology to determine the parameters and the complete meaning of the coefficient are given on the Supporting Information. The separation factor $\alpha_{\mathrm{H}_{2} \mathrm{O} / \mathrm{EtOH}}$ is a measure of the quality of the separation that the membranes provides ${ }^{58}$ and is defined as

$$
\alpha_{\mathrm{AB}}=\frac{y_{\mathrm{A}} / y_{\mathrm{B}}}{x_{\mathrm{A}} / x_{\mathrm{B}}}
$$

where $x_{\mathrm{A}}$ and $x_{\mathrm{B}}$ are the weight fractions of components in the feed solution (in wt \%) and $y_{\mathrm{A}}$ and $y_{\mathrm{B}}$ the weight fractions of components in the permeate (in wt \%). In order to compare the separation efficiency of the investigated membranes, the PSI expressed by following equation was used:

$$
\text { PSI }=J\left(\alpha_{\mathrm{AB}}-1\right)
$$

where $J$ is the total permeate flux and $\alpha_{\mathrm{AB}}$ is the separation factor. The parameters evaluated for the pristine and hybrid sodium alginate membranes filled with different amounts of $\mathrm{Fe}_{x} \mathrm{~N} / \mathrm{C}_{\mathrm{XG}}$ are shown in Table 3 and Figures 7 and 8.

From the above results, the bare sodium alginate membrane appears to be moderately selective and applicable in the pervaporative dehydration of ethanol with a separation factor of 26.6 and a PSI of $18.2 \mathrm{~kg} \mathrm{~m}^{-2} \mathrm{~h}^{-1}$. The addition of the $\mathrm{Fe}_{x} \mathrm{~N} /$ $\mathrm{C}_{\mathrm{XG}}$ filler into the alginate membrane has a positive impact on its separation properties. The water solubility in the membrane decreases with the filler content and reaches down to 3 times smaller values with respect to the bare membrane (Figure 7a), and the water diffusion coefficient sensibly increases with the filler loading (Figure $7 \mathrm{~b}$ ) and reaches an 18 times larger value with respect to the bare membrane with a filler loading of $10 \%$ $\mathrm{w} / \mathrm{w}$. In contrast, for ethanol molecules, the solubility coefficient increases with the filler content (Figure 7a) and the ethanol
Table 3. Estimated Transport and Performance Parameters for Alginate Membranes Filled with $\mathrm{Fe}_{x} \mathrm{~N} / \mathrm{C}_{\mathrm{XG}}$ Amounts

\begin{tabular}{lccccc} 
& \multicolumn{5}{c}{$\mathrm{Fe}_{x} \mathrm{~N} / \mathrm{C}_{\mathrm{XG}}$ content $(\mathrm{wt} \%)$} \\
\cline { 2 - 6 } & 0 & 1 & 3 & 5 & 10 \\
$J_{\mathrm{N}}\left(\mathrm{kg} \mathrm{m}^{-2} \mathrm{~h}^{-1}\right)$ & 0.71 & 1.03 & 1.42 & 1.65 & 2.15 \\
$P_{\text {water }}\left(\times 10^{5}\right.$ barrer $)$ & 4.83 & 18.83 & 20.48 & 22.5 & 26.25 \\
$P_{\text {EtOH }}\left(\times 10^{5}\right.$ barrer $)$ & 0.23 & 0.87 & 0.94 & 1.24 & 5.07 \\
$D_{\text {water }}\left(\times 10^{7} \mathrm{~cm}^{2} \mathrm{~s}^{-1}\right)$ & 1.44 & 9.28 & 12.24 & 19.26 & 25.61 \\
$D_{\text {EtOH }}\left(\times 10^{7} \mathrm{~cm}^{2} \mathrm{~s}^{-1}\right)$ & 0.22 & 0.48 & 0.42 & 0.42 & 1.25 \\
$S_{\text {water }}\left(\mathrm{cm}_{\mathrm{STP}}^{3} \mathrm{~cm}^{-3}\right.$ & 335.4 & 202.9 & 167.3 & 116.8 & 102.5 \\
$\left.\mathrm{cmHg}^{-1}\right)$ & & & & & \\
$S_{\text {EtOH }}\left(\mathrm{cm}_{\mathrm{STP}}{ }^{3} \mathrm{~cm}^{-3}\right.$ & 104.5 & 183.0 & 224.0 & 293.7 & 406.1 \\
$\left.\mathrm{cmHg}^{-1}\right)$ & & & & & \\
$S_{\mathrm{c}}$ & 21.0 & 21.64 & 21.78 & 18.14 & 5.18 \\
$\alpha_{\text {water } / \mathrm{EtOH}}$ & 26.65 & 57.88 & 65.42 & 28.84 & 12.15 \\
PSI $\left(\mathrm{kg} \mathrm{m}^{-2} \mathrm{~h}^{-1}\right)$ & 18.2 & 58.6 & 91.5 & 45.9 & 24.0 \\
\hline
\end{tabular}

(a)

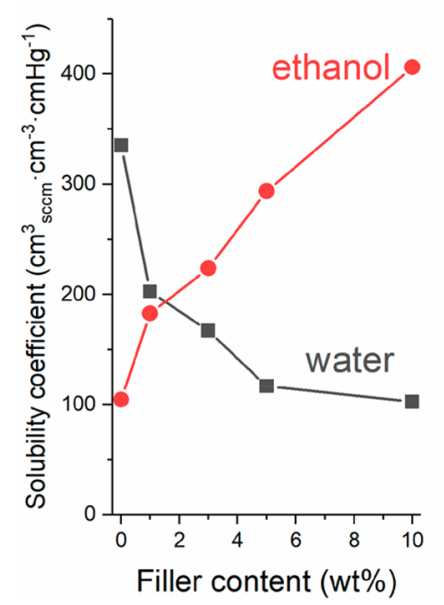

(b)

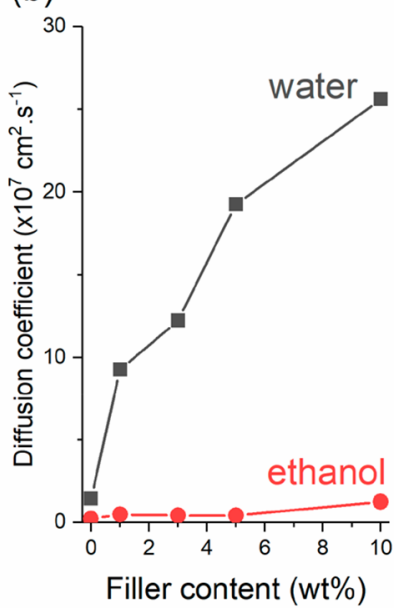

Figure 7. (a) Solubility and (b) water/ethanol diffusion coefficients in hybrid alginate membranes as a function of the $\mathrm{Fe}_{x} \mathrm{~N} / \mathrm{C}_{\mathrm{XG}}$ filler loading.
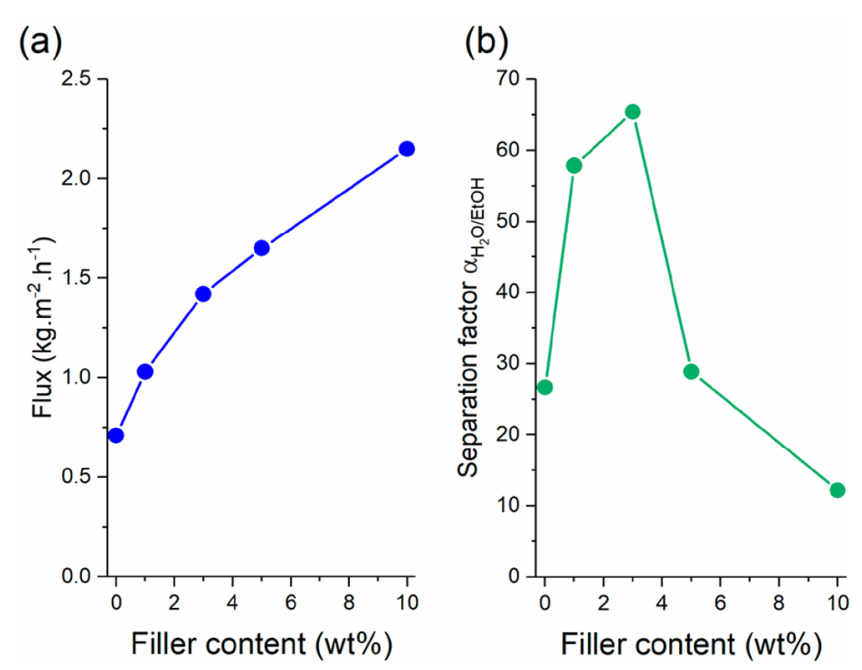

Figure 8. (a) Water/ethanol flux and (b) separation factor in hybrid alginate membranes as a function of the $\mathrm{Fe}_{x} \mathrm{~N} / \mathrm{C}_{\mathrm{XG}}$ filler loading.

diffusion coefficient only slightly increases with the filler loading (Figure $7 \mathrm{~b}$ ). The results show that the $\mathrm{Fe}_{x} \mathrm{~N} / \mathrm{C}_{\mathrm{XG}}$ filler promotes the separation process of the ethanol/water mixture. This effect is attributed to the magnetic properties of iron nitride 
nanoparticles. Specifically, each molecule has a specific magnetic characteristic due to the spin and orbital magnetic moments of their electrons and nuclei. Toledo et al. ${ }^{60}$ studied the influence of a magnetic field on the interactions of the water molecules using theoretical calculations and the alterations on the physicochemical properties through experimental measures of vaporization enthalpy, viscosity, and surface tension. They noticed that the magnetic field weakened the stronger intracluster hydrogen bonds, breaking the larger clusters on the smaller ones with stronger intercluster hydrogen bonds. Smaller clusters of water molecules can easier penetrate through the membrane and thus may be responsible for the more effective separation of the water/ethanol mixture..

The water/ethanol flux in the membrane clearly increases with the $\mathrm{Fe}_{x} \mathrm{~N} / \mathrm{C}_{\mathrm{XG}}$ filler content (Figure 8a). This is ascribed to the free volume created by the filler into the polymer matrix, which facilitates transport of the molecules. While the flux constantly increases with the $\mathrm{Fe}_{x} \mathrm{~N} / \mathrm{C}_{\mathrm{XG}}$ loading, the separation factor value only increases up to $3 \% \mathrm{w} / \mathrm{w}$ loading (Figure $8 \mathrm{~b}$ ). The reduction of the membrane selectivity at high loading is ascribed to the excessively high diffusion of water and ethanol species. The best result is thus obtained for the alginate membrane filled with $3 \% \mathrm{w} / \mathrm{w}$ of $\mathrm{Fe}_{x} \mathrm{~N} / \mathrm{C}_{\mathrm{XG}}$, allowing for a separation factor of 65.4 , a PSI of $91.5 \mathrm{~kg} \mathrm{~m}^{-2} \mathrm{~h}^{-1}$, and a relatively high flux of $1.4 \mathrm{~kg} \mathrm{~m}^{-2} \mathrm{~h}^{-1}$, demonstrating an effective membrane for ethanol dehydration, based on cheap and nontoxic materials.

\section{CONCLUSION}

Iron nitride nanoparticles have been synthesized by ICP plasma degradation of iron acetylacetonate on a carbon xerogel as the support. A series of $\mathrm{Fe}_{x} \mathrm{~N} / \mathrm{C}_{\mathrm{XG}}$ samples have been investigated by varying the pumping rate to tune the working pressure in the $\mathrm{Ar} / \mathrm{NH}_{3}$ plasma from 6 to $45 \mathrm{mT}$ Torr. The synthesis pressure is found to significantly affect the nanoparticle nucleation rate and crystallinity of the $\mathrm{Fe}_{x} \mathrm{~N}$ nanoparticles, thus finally affecting their ferromagnetic properties. The $M(H)$ loop curves indicate that the coercivity, remanent magnetization, and saturation magnetization increase with the plasma treatment working pressure. Because of its versatility, the proposed plasma-based methodology can be easily adapted to other metal precursors and substrates. In addition, it has a rather low energetic and environmental impact (solvent-free). Finally, the optimized $\mathrm{Fe}_{x} \mathrm{~N} / \mathrm{C}_{\mathrm{XG}}$ composite was applied as an effective filler for the alginate membrane for pervaporative ethanol dehydration. At the optimum loading of $3 \% \mathrm{w} / \mathrm{w}$, the performance of a pristine alginate membrane could be considerably enhanced, in terms of the selectivity, separation index, and flux. These results demonstrate that the synthesized magnetic material is an efficient, cheap, and nontoxic filler for such hybrid membranes.

\section{ASSOCIATED CONTENT}

\section{S Supporting Information}

The Supporting Information is available free of charge on the ACS Publications website at DOI: 10.1021/acsanm.9b00385.

Fitting parameters of magnetic measurement (XLSX) Pervaporation measurement setup and a minimum of the theoretical background on the method (PDF)

\section{AUTHOR INFORMATION}

\section{Corresponding Author}

*E-mail: emile.haye@unamur.be.

\section{ACKNOWLEDGMENTS}

The authors acknowledge the Synthesis, Irradiation \& Analysis of Materials and Physico-Chemical Characterization platforms of the University of Namur for XPS and XRD facilities. The Centre de Compétences Magnétisme et Cryogénie, Institut Jean Lamour, Université de Lorraine, is acknowledged for magnetometry measurements. The authors thank the ICEEL Carnot Institute for financial support.

\section{REFERENCES}

(1) Nguyen, D. P.; Tran, Q. T.; Trinh, X. S.; Hoang, T. C.; Nguyen, H. N.; Nguyen, H. H. Crystallization and Magnetic Properties of Amorphous Iron-Chromium Oxide Nanoparticles Synthesized by Sonochemistry. Adv. Nat. Sci.: Nanosci. Nanotechnol. 2012, 3 (1), 015017.

(2) Machala, L.; Zboril, R.; Gedanken, A. Amorphous Iron(III) Oxide A Review. J. Phys. Chem. B 2007, 111 (16), 4003-4018.

(3) Panchal, V.; Bhandarkar, U.; Neergat, M.; Suresh, K. G. Synthesis of Iron Oxide Nanoparticles from Iron Acetylacetonate and Cyclopentadienyliron Dicarbonyl Dimer in Low Pressure Plasma - Effect of Plasma Parameters on Morphology and Magnetic Properties. Int. J. Nanosci. 2015, 14 (03), 1550004.

(4) Bayer, B. C.; Baehtz, C.; Kidambi, P. R.; Weatherup, R. S.; Mangler, C.; Kotakoski, J.; Goddard, C. J. L.; Caneva, S.; CabreroVilatela, A.; Meyer, J. C.; et al. Nitrogen Controlled Iron Catalyst Phase during Carbon Nanotube Growth. Appl. Phys. Lett. 2014, 105 (14), 143111.

(5) Li, J.; Yu, F.; Wang, M.; Lai, Y.; Wang, H.; Lei, X.; Fang, J. Highly Dispersed Iron Nitride Nanoparticles Embedded in N Doped Carbon as a High Performance Electrocatalyst for Oxygen Reduction Reaction. Int. J. Hydrogen Energy 2017, 42 (5), 2996-3005.

(6) Tsai, C.-W.; Tu, M.-H.; Chen, C.-J.; Hung, T.-F.; Liu, R.-S.; Liu, W.-R.; Lo, M.-Y.; Peng, Y.-M.; Zhang, L.; Zhang, J.; et al. NitrogenDoped Graphene Nanosheet-Supported Non-Precious Iron Nitride Nanoparticles as an Efficient Electrocatalyst for Oxygen Reduction. RSC Adv. 2011, 1 (7), 1349-1357.

(7) Zhang, B.; Xiao, C.; Xie, S.; Liang, J.; Chen, X.; Tang, Y. IronNickel Nitride Nanostructures in Situ Grown on Surface-RedoxEtching Nickel Foam: Efficient and Ultrasustainable Electrocatalysts for Overall Water Splitting. Chem. Mater. 2016, 28 (19), 6934-6941.

(8) Chen, Q.; Wang, R.; Yu, M.; Zeng, Y.; Lu, F.; Kuang, X.; Lu, X. Bifunctional Iron-Nickel Nitride Nanoparticles as Flexible and Robust Electrode for Overall Water Splitting. Electrochim. Acta 2017, 247, 666-673.

(9) Dong, Y.; Wang, B.; Zhao, K.; Yu, Y.; Wang, X.; Mai, L.; Jin, S. AirStable Porous Fe2N Encapsulated in Carbon Microboxes with High Volumetric Lithium Storage Capacity and a Long Cycle Life. Nano Lett. 2017, 17 (9), 5740-5746.

(10) Liu, G.; Gao, J.; Ai, H.; Chen, X. Applications and Potential Toxicity of Magnetic Iron Oxide Nanoparticles. Small 2013, 9 (9-10), 1533-1545.

(11) Zieschang, A.-M.; Bocarsly, J. D.; Dürrschnabel, M.; MolinaLuna, L.; Kleebe, H.-J.; Seshadri, R.; Albert, B. Nanoscale Iron Nitride, $\varepsilon$-Fe3N: Preparation from Liquid Ammonia and Magnetic Properties. Chem. Mater. 2017, 29 (2), 621-628.

(12) Kortshagen, U. R.; Sankaran, R. M.; Pereira, R. N.; Girshick, S. L.; Wu, J. J.; Aydil, E. S. Nonthermal Plasma Synthesis of Nanocrystals: Fundamental Principles, Materials, and Applications. Chem. Rev. 2016, 116 (18), 11061-11127. 
(13) Cvelbar, U.; Levchenko, I.; Filipič, G.; Mozetič, M.; Ostrikov, K. Plasma Control of Morpho-Dimensional Selectivity of Hematite Nanostructures. Appl. Phys. Lett. 2012, 100 (24), 243103.

(14) Wang, Q.; Song, M.; Chen, C.; Wei, Y.; Zuo, X.; Wang, X. Synthesis of Graphene-Based Pt Nanoparticles by a One-Step in Situ Plasma Approach under Mild Conditions. Appl. Phys. Lett. 2012, 101 (3), 033103.

(15) Pourzahedi, L.; Eckelman, M. J. Comparative Life Cycle Assessment of Silver Nanoparticle Synthesis Routes. Environ. Sci.: Nano 2015, 2 (4), 361-369.

(16) Woodard, A.; Xu, L.; Barragan, A. A.; Nava, G.; Wong, B. M.; Mangolini, L. On the Non-Thermal Plasma Synthesis of Nickel Nanoparticles. Plasma Processes Polym. 2018, 15 (1), 1700104.

(17) Mandal, R.; O’Shea, K.; Anthony, R. Silicon Nitride-Capped Silicon Nanocrystals via a Nonthermal Dual-Plasma Synthesis Approach. J. Vac. Sci. Technol., A 2018, 36 (5), 051303.

(18) Pi, X. D.; Kortshagen, U. Nonthermal Plasma Synthesized Freestanding Silicon-Germanium Alloy Nanocrystals. Nanotechnology 2009, 20 (29), 295602.

(19) Haye, E.; Busby, Y.; da Silva Pires, M.; Bocchese, F.; Job, N.; Houssiau, L.; Pireaux, J.-J. Low-Pressure Plasma Synthesis of Ni/C Nanocatalysts from Solid Precursors: Influence of the Plasma Chemistry on the Morphology and Chemical State. ACS Appl. Nano Mater. 2018, 1 (1), 265-273.

(20) Laurent-Brocq, M.; Job, N.; Eskenazi, D.; Pireaux, J.-J. Pt/C Catalyst for PEM Fuel Cells: Control of Pt Nanoparticles Characteristics through a Novel Plasma Deposition Method. Appl. Catal., B 2014, 147, 453-463.

(21) Busby, Y.; Stergiopoulos, V.; Job, N.; Pireaux, J. J. Low Pressure Plasma Synthesis of Pt/C Catalysts for Fuel Cells Applications. ISPC22 Conference proceeding; 2016.

(22) Jack, K. H. The Iron-Nitrogen System: The Crystal Structures of $\varepsilon$-Phase Iron Nitrides. Acta Crystallogr. 1952, 5 (4), 404-411.

(23) Leineweber, A.; Jacobs, H.; Hüning, F.; Lueken, H.; Kockelmann, W. Nitrogen Ordering and Ferromagnetic Properties of $\epsilon$-Fe3N1+x $(0.10 \leq x \leq 0.39)$ and $\epsilon$-Fe3(N0.80C0.20)1.38. J. Alloys Compd. 2001, $316(1), 21-38$.

(24) Hendricks, S. B.; Kosting, P. R. The Crystal Structure of Fe2P, Fe2N, Fe3N and FeB. Z. Kristallogr. - Cryst. Mater. 1930, 74, 511-533.

(25) Jacobs, H.; Rechenbach, D.; Zachwieja, U. Structure Determination of $\Gamma^{\prime}$-Fe4N and $\epsilon$-Fe3N. J. Alloys Compd. 1995, 227 (1), 10-17.

(26) Bobo, J.-F.; Chatbi, H.; Vergnat, M.; Hennet, L.; Lenoble, O.; Bauer, P.; Piecuch, M. Magnetic and Structural Properties of Iron Nitride Thin Films Obtained by Argon-nitrogen Reactive Radiofrequency Sputtering. J. Appl. Phys. 1995, 77 (10), 5309-5313.

(27) Naganuma, H.; Nakatani, R.; Endo, Y.; Kawamura, Y.; Yamamoto, M. Structure and Magnetic Properties of Iron Nitride Films Prepared by Reactive Dc Magnetron Sputtering. Jpn. J. Appl. Phys. 2004, 43 (7R), 4166.

(28) Moulder, J. F.; Stickle, W. F.; Sobol, P. E.; Bomben, K. D. Handbook of X Ray Photoelectron Spectroscopy: A Reference Book of Standard Spectra for Identification and Interpretation of XPS Data, reissue ed.; Physical Electronics: Eden Prairie, MN, 1995.

(29) Torres, J.; Perry, C. C.; Bransfield, S. J.; Fairbrother, D. H. LowTemperature Oxidation of Nitrided Iron Surfaces. J. Phys. Chem. B 2003, 107 (23), 5558-5567.

(30) Biesinger, M. C.; Payne, B. P.; Grosvenor, A. P.; Lau, L. W. M.; Gerson, A. R.; Smart, R. S. C. Resolving Surface Chemical States in XPS Analysis of First Row Transition Metals, Oxides and Hydroxides: Cr, Mn, Fe, Co and Ni. Appl. Surf. Sci. 2011, 257 (7), 2717-2730.

(31) Prieto, P.; Marco, J. F.; Sanz, J. M. Synthesis and characterization of iron nitrides. An XRD, Mössbauer, RBS and XPS characterization. Surf. Interface Anal. 2008, 40 (3-4), 781-785.

(32) Esaka, F.; Furuya, K.; Shimada, H.; Imamura, M.; Matsubayashi, N.; Sato, H.; Nishijima, A.; Kawana, A.; Ichimura, H.; Kikuchi, T. Comparison of Surface Oxidation of Titanium Nitride and Chromium Nitride Films Studied by X-Ray Absorption and Photoelectron Spectroscopy. J. Vac. Sci. Technol., A 1997, 15 (5), 2521-2528.
(33) Milošev, I.; Strehblow, H.-H.; Navinšek, B. Comparison of TiN, $\mathrm{ZrN}$ and CrN Hard Nitride Coatings: Electrochemical and Thermal Oxidation. Thin Solid Films 1997, 303 (1), 246-254.

(34) Graat, P. C. J.; Somers, M. A. J.; Mittemeijer, E. J. The Initial Oxidation of $\varepsilon$-Fe2N1-x: An XPS Investigation. Appl. Surf. Sci. 1998, 136 (3), 238-259.

(35) Prieto, P.; Kirby, R. E. X-ray Photoelectron Spectroscopy Study of the Difference between Reactively Evaporated and Direct Sputterdeposited TiN Films and Their Oxidation Properties. J. Vac. Sci. Technol., A 1995, 13 (6), 2819-2826.

(36) Panda, R. N.; Gajbhiye, N. S. Magnetic Properties of Single Domain $\varepsilon$-Fe3N Synthesized by Borohydride Reduction Route. J. Appl. Phys. 1997, 81 (1), 335-339.

(37) Bhattacharyya, S.; Shivaprasad, S. M.; Gajbhiye, N. S. Variation of Magnetic Ordering in $\varepsilon-\mathrm{Fe}_{3} \mathrm{~N}$ Nanoparticles. Chem. Phys. Lett. 2010, 496, 122-127.

(38) Qi, Y.; Liu, X.; Huang, W.; Lu, H.; Gao, J. The Preparation and Ferromagnetism of Single Crystal $\varepsilon$-Fe3N(111) Film on SrTiO3(100) Substrate. Vacuum 2016, 133, 13-17.

(39) Gudmundsson, J. T. On the Effect of the Electron Energy Distribution on the Plasma Parameters of an Argon Discharge: A Global (Volume-Averaged) Model Study. Plasma Sources Sci. Technol. 2001, 10 (1), 76.

(40) Puliyalil, H.; Cvelbar, U. Selective Plasma Etching of Polymeric Substrates for Advanced Applications. Nanomaterials 2016, 6 (6), 108.

(41) Lopez, T.; Mangolini, L. Crystallization Kinetics of PlasmaProduced Amorphous Silicon Nanoparticles. MRS Online Proc. Libr. 2013, 1536, 213-218.

(42) Awadallah-F, A.; Al-Muhtaseb, S. A.; Jeong, H.-K. Selective Adsorption of Carbon Dioxide, Methane and Nitrogen Using Resorcinol-Formaldehyde-Xerogel Activated Carbon. Adsorption 2017, 23 (7-8), 933-944.

(43) Alegre, C.; Gálvez, M. E.; Baquedano, E.; Moliner, R.; Pastor, E.; Lázaro, M. J. Oxygen-Functionalized Highly Mesoporous Carbon Xerogel Based Catalysts for Direct Methanol Fuel Cell Anodes. J. Phys. Chem. C 2013, 117 (25), 13045-13058.

(44) Alegre, C.; Sebastián, D.; Baquedano, E.; Gálvez, M. E.; Moliner, R.; Lázaro, M. Tailoring Synthesis Conditions of Carbon Xerogels towards Their Utilization as Pt-Catalyst Supports for Oxygen Reduction Reaction (ORR). Catalysts 2012, 2 (4), 466-489.

(45) Yook, J. Y.; Jun, J.; Kwak, S. Amino Functionalization of Carbon Nanotube Surfaces with NH3 Plasma Treatment. Appl. Surf. Sci. 2010, 256 (23), 6941-6944.

(46) Felten, A.; Bittencourt, C.; Pireaux, J. J.; Van Lier, G.; Charlier, J. C. Radio-Frequency Plasma Functionalization of Carbon Nanotubes Surface O2, NH3, and CF4 Treatments. J. Appl. Phys. 2005, 98 (7), 074308 .

(47) Lin, Y.-C.; Lin, C.-Y.; Chiu, P.-W. Controllable Graphene NDoping with Ammonia Plasma. Appl. Phys. Lett. 2010, 96 (13), 133110.

(48) Kramer, N. J.; Anthony, R. J.; Mamunuru, M.; Aydil, E. S.; Kortshagen, U. R. Plasma-Induced Crystallization of Silicon Nanoparticles. J. Phys. D: Appl. Phys. 2014, 47 (7), 075202.

(49) Rohith Vinod, K.; Saravanan, P.; Sakar, M.; Balakumar, S. Insights into the Nitridation of Zero-Valent Iron Nanoparticles for the Facile Synthesis of Iron Nitride Nanoparticles. RSC Adv. 2016, 6 (51), 45850-45857.

(50) Brown, W. F. Theory of the Approach to Magnetic Saturation. Phys. Rev. 1940, 58, 736-743.

(51) Zhang, H.; Zeng, D.; Liu, Z. The Law of Approach to Saturation in Ferromagnets Originating from the Magnetocrystalline Anisotropy. J. Magn. Magn. Mater. 2010, 322 (16), 2375-2380.

(52) Schliehe, C.; Yuan, J.; Glatzel, S.; Siemensmeyer, K.; Kiefer, K.; Giordano, C. Iron Nitride and Carbide: From Crystalline Nanoparticles to Stable Aqueous Dispersions. Chem. Mater. 2012, 24 (14), 27162721.

(53) Ningthoujam, R. S.; Gajbhiye, N. S. Magnetic Study of Single Domain $\varepsilon-\mathrm{Fe}_{3} \mathrm{~N}$ Nanoparticles Synthesized by Precursor Technique. Mater. Res. Bull. 2008, 43 (5), 1079-1085. 
(54) Robbins, M.; White, J. G. Magnetic Properties of Epsilon-Iron Nitride. J. Phys. Chem. Solids 1964, 25 (7), 717-720.

(55) Rohith Vinod, K.; Saravanan, P.; Sakar, M.; Vinod, V. T. P.; Cernik, M.; Balakumar, S. Large Scale Synthesis and Formation Mechanism of Highly Magnetic and Stable Iron Nitride $(\varepsilon$-Fe3N) Nanoparticles. RSC Adv. 2015, 5 (69), 56045-56048.

(56) Li, D.; Zhang, Z. D.; Li, W. F.; Feng, W. J.; Choi, C. J.; Kim, B. K. Electrical and Magnetic Properties of $\varepsilon$-Fe3N Nanoparticles Synthesized by Chemical Vapor Condensation Process. J. Magn. Magn. Mater. 2006, 307 (1), 128-133.

(57) Yu, Z. Q.; Zhang, J. R.; Du, Y. W. Magnetic Properties and Preparation of Fe3N Compound. J. Magn. Magn. Mater. 1996, 159 (12), L8-L10.

(58) Dudek, G.; Turczyn, R.; Gnus, M.; Konieczny, K. Pervaporative Dehydration of Ethanol/Water Mixture through Hybrid Alginate Membranes with Ferroferic Oxide Nanoparticles. Sep. Purif. Technol. 2018, 193, 398-407.

(59) Dudek, G.; Gnus, M.; Turczyn, R.; Strzelewicz, A.; Krasowska, M. Pervaporation with Chitosan Membranes Containing Iron Oxide Nanoparticles. Sep. Purif. Technol. 2014, 133, 8-15.

(60) Toledo, E. J. L.; Ramalho, T. C.; Magriotis, Z. M. Influence of Magnetic Field on Physical-Chemical Properties of the Liquid Water: Insights from Experimental and Theoretical Models. J. Mol. Struct. 2008, 888 (1), 409-415. 